\title{
"PERDI AS ESPERANÇAS": O TESTEMUNHO E A POESIA DE ALEX POLARI
}

\author{
Lívia Volkers ${ }^{1}$ \\ Wilberth Salgueiro ${ }^{2}$
}

Resumo: O artigo expõe e examina alguns traços da literatura de testemunho, em especial aqueles mais estreitamente vinculados ao âmbito germânico, mas estendendo-os ao contexto brasileiro. A seguir, propõe uma análise do poema "12.207", presente no livro Inventário de cicatrizes (1978), de Alex Polari. Conclui, mostrando que a resistência à barbárie e à coisificação pode se dar a ver e se fortalecer a partir de registros diversos, desde os relatos testemunhais orais ou narrativos de sobreviventes de catástrofes, até poemas que, partindo de dramas pessoais, representam a história de uma grande dor coletiva.

Palavras-chave: Literatura de testemunho; poesia de testemunho; Alex Polari.

Abstract: This article disclosures and examines some aspects of literary testimony, particularly those most closely linked to the German scope, however extending them to the Brazilian context as well. It presents an analysis of the poem "12 207", from the book Inventário de cicatrizes (Scars Inventory) (1978) by Alex Polari, in order to conclude that not only can resistance to barbarism and objectification come to light, but also gain strength through testimonies that range from survivors' oral or written reports, to, even, poems that, drawing from personal dramas, represent the history of a great collective pain.

Keywords: Literary testimony; testimonial poetry; Alex Polari.

\footnotetext{
${ }^{1}$ Graduanda em Letras-Português na UFES. Bolsista de Iniciação Científica do CNPq. E-mail: liviavolkers@hotmail.com

${ }^{2}$ Doutor, professor de Literatura brasileira na UFES. Bolsista de Produtividade em Pesquisa do CNPq. E-mail: wilberthcfs@gmail.com
} 
O século $\mathrm{XX}$ foi cunhado, muito a propósito, de Era dos extremos por Eric Hobsbawm, por nele ter ocorrido uma série de horrores, dos quais o nazismo possivelmente configura como o mais eloquente exemplo. Parte dos sobreviventes deste bestial empreendimento, tanto em nome de seus finados companheiros quanto para reaver certa tranquilidade mental e emocional, tomada quase por irrecuperável, têm se esforçado em relatar, por escrito ou oralmente, detalhes do inferno a que foram atirados - esse conjunto de relatos constitui, em sentido lato, o testemunho. Em linhas gerais, trata-se de uma poderosa ferramenta à força da qual os sobreviventes põem às claras as barbaridades que conheceram nos Lager (campos de concentração) e cujos indícios de existência os responsáveis cuidaram de obliterar. Como já observado por Márcio Seligmann-Silva (2003), ainda que restasse alguma evidência, os nazistas conheciam que a sua máquina de matar erigiria a desconfiança geral, à conta, precisamente, de seu caráter absurdo e impossível, conforme conta Primo Levi neste excerto de Os afogados e os sobreviventes (1990, p. 9):

Seja qual for o fim desta guerra, a guerra contra vocês nós ganhamos; ninguém restará para dar testemunho, mas, mesmo que alguém escape, o mundo não lhe dará crédito [...]. Ainda que fiquem algumas provas e sobreviva alguém, as pessoas dirão que os fatos narrados são tão monstruosos que não merecem confiança; dirão que são exagerados e propaganda aliada e acreditarão em nós que negaremos tudo, e não em vocês. Nós é que ditaremos a história dos Lager.

Antes, portanto, de partir para a análise do poema "12.207", do exguerrilheiro Alex Polari de Alverga, vítima da ditadura militar brasileira, convém dedicar algumas linhas ao trato desta nova perspectiva da literatura, estreitamente vinculada ao evento do Holocausto, emblema incontornável de desumanidade e extermínio sistemático de seres humanos.

Em primeiro lugar, entendamos que o discurso em torno da noção de testemunho pode seguir orientações assaz diversas, o que depende objetivamente do contexto à luz do qual o consideramos. Em "Literatura e trauma: um novo paradigma" (2005), Márcio Seligmann-Silva põe na berlinda tais propensões discursivo-teóricas, atentando para a intraduzibilidade dos termos Zeugnis e testimonio. Segundo o autor, na teoria literária de âmbito 
germânico o testemunho responde pelo nome de Zeugnis e é pensado centralmente sob o horizonte da Shoah, que consistiu no projeto de extermínio nazista perpetrado contra os judeus e contra outros grupos étnicos. Por essa razão, a ênfase nessa perspectiva recai sobre o trauma - mais a afasia dele resultante - que acometera os sobreviventes do nazismo e, também, sobre o trabalho de memória que a verificação de tal fenômeno solicita, de modo que conceitos de psicanálise devem ser acionados. Por outro lado, em âmbito latino-americano o testemunho atende pelo nome de testimonio, possuindo outras especificidades, pois advoga a favor das chamadas minorias, denunciando as situações de opressão que elas experimentam amargamente no dia a dia, há décadas e, mesmo, séculos. Em ambos os casos, entretanto, o testemunho se presta ao propósito de dar expressão aos silenciados pelo discurso histórico oficial, ditado pelos vencedores, cujo interesse maior reside em registrar os acontecimentos considerados de grande monta, atinentes a realizações monumentais.

Uma entre as discussões que notadamente frequentam a teoria em torno da literatura testemunhal diz respeito à questão da possibilidade de narração do evento. Sem o registro, naturalmente, a transmissão do que foi o Holocausto - embora não possamos falar em sua descrição exata, tanto menos no terreno do testemunho - não seria alcançável. Desta forma, as reflexões teóricas se orientam no sentido de mostrar por que a transmissão da experiência se tem feito fundamental e, de uns tempos para cá, urgente, e também no sentido de deliberar sobre os aspectos formais que caracterizam uma escrita desta natureza, obrigada a uma "linguagem da dor", cuja razão primária de existir é a eclosão de eventos-limite (SALGUEIRO, 2013). Esta linguagem não tenciona fazer uma descrição nem "objetiva" nem linear do passado, primando antes pela fragmentação do discurso, por aspectos que reflitam a mutilação sofrida pelas vítimas, mutilação que compromete também sua capacidade de simbolização. Além disso, uma narração que privilegie a fragmentação do discurso expressa e denuncia o caráter arbitrário e traumático do ocorrido, contrariamente à adoção de uma narração causal e linear dos fatos, procedimento que poderia mascarar tal caráter.

Basicamente, são três as razões que fazem da narração escrita algo tão inadiável: o dever, da parte dos sobreviventes, de prestar solidariedade aos Revista Eletrônica Literatura e Autoritarismo: Narrativa Testemunhal e Relações Históricas - ISSN 1679-849X |53| http://cascavel.ufsm.br/revistas/ojs-2.2.2/index.php/LA/index 
que não gozaram de destino afim (o de continuar vivo); o aspecto terapêutico embora doloroso - que tal escrita possibilita (de tentar elaborar o luto); e, por fim, a necessidade de divulgar os fatos para evitar a reincidência de catástrofes (cujas causas permanecem entre nós, como demonstra Theodor Adorno em "O que significa elaborar o passado" (1995).

Sobre a primeira razão em pauta, ela esbarra em outro princípio caro à literatura de testemunho, que assenta na relação paradoxal entre a impossibilidade e a necessidade de narrar, tarefa aporética com que os sobreviventes se deparam. Tal óbice há que ser galgado sob os apelos de certo princípio ético, que consiste em narrar o ocorrido, conquanto doloroso e inexprimível, em atenção àqueles que foram privados deste direito - os aniquilados; as testemunhas do massacre em seu mais alto grau, cuja dignidade foi cruelmente arrasada pelos nazistas. Noutras palavras, em que pese a intraduzibilidade do ocorrido - pois tais bestialidades (por cujo paroxismo os nazistas respondem) restaram irredutíveis à nossa linguagem e à nossa simbologia - há que ser feito um esforço nesse sentido, na medida em que este gesto, como observou Jeanne Marie Gagnebin em "O rastro e a cicatriz: metáforas da memória" (2006), pode fazer as vezes de sepulcro aos que tiveram os rastros de sua existência totalmente obliterados. Falta, portanto, um registro fúnebre das memórias que foram apagadas adrede pelos nazistas, tarefa confiada aos sobreviventes. Esta primeira razão é comandada, sobretudo, pelo senso ético.

Relativamente à segunda razão, esta escrita narrativa encerra um componente terapêutico assaz providencial aos sobreviventes traumatizados, cujo testemunho, conforme vaticinavam seus pesadelos, não encontra acolhida/escuta mesmo nos familiares, de sorte que não conseguem superar a viva lembrança dos campos de concentração (ou de outras inúmeras torturas, se pensarmos nas múltiplas formas e exemplos de violência do homem contra o homem). Este medo de não serem escutados, provocado pelo desejo ardente de tornar os outros conhecedores, já os acompanhava nos campos, conforme conta Primo Levi no prefácio de seu É isto um homem? (1988, p. 7):

A necessidade de contar "aos outros", de tornar "os outros" participantes, alcançou entre nós, antes e depois da libertação, 
caráter de impulso imediato e violento, até o ponto de competir com outras necessidades elementares. O livro foi escrito para satisfazer essa necessidade em primeiro lugar, portanto, com a finalidade de liberação interior.

Em O que resta de Auschwitz? (2008), Giorgio Agamben informa que a busca pela sobrevivência, da parte das vítimas dos campos de extermínio, provinha justamente da vontade de dar testemunho. A testemunha, segundo Agamben, pode ser identificada segundo dois termos latinos: testis, do qual derivou o nosso "testemunha", atinente a um terceiro que se coloca entre dois contendores num litígio, e superstes, cujo significado se aproxima da ideia de sobrevivente, por designar o indivíduo que enfrentou determinada situação até seu cabo. Também podemos falar em testemunha solidária, como aquele que não rejeita a narração do outro, mas que a acolhe e a leva adiante, valendonos de reflexão de Jeanne Marie Gagnebin, em "Memória, história, testemunho" (2006).

A expulsão dos civis de suas casas, a sua transferência dos guetos para os campos e, uma vez lá, as milhares e milhares de mortes planejadas e casuais, o trabalho escravo, as precárias condições de alojamento, a fome, a sede, o frio; toda essa saraivada de "punições" (desumanas, bárbaras, coisificantes) sobreveio, abatendo feito a animais os judeus e outros "escolhidos", contra o que eles, inermes, nada puderam fazer - o veredito partia do próprio governo hitlerista. A absurdidade que caracteriza tal programa, de motivações que escapam à nossa compreensão de humanidade; o doloroso temor de que isto venha a se repetir (afinal de contas, nada obstou que o evento ocorresse com tal dimensão, com um Estado colocando sua máquina a serviço de um genocídio organizado); a falta de interesse da parte dos outros pela escuta; tudo isso repisa a dor e a solidão em que incorrem os sobreviventes da hecatombe, prendendo-os tanto mais àquela realidade tétrica, inclemente e tentacular, de que eles foram presas. Os sobreviventes da Shoah foram livrados dos campos de concentração apenas sob o ponto de vista físico, pois a lembrança traumática do Lager não cessa de sufocá-los. Compartilhar a memória da dor significaria também mitigar o peso do fardo.

Sobre a terceira e última razão, a narração deve ser realizada para opor obstáculos à possibilidade de reincidência do morticínio, pois o nazismo, na 
esteira de outros empreendimentos macabros, foi tão-só aparentemente vencido, mas as suas motivações continuam de atalaia. Por isso é tão importante que os sobreviventes não se furtem a esse "dever de memória" e deem testemunho daquilo que os vitimou, de modo a blindar o campo contra um contingente de discursos que nega a existência da Shoah, sob a alegação de que os campos de concentração eram, na verdade, campos de batalha. Sem relatos que atestem o que verdadeiramente foi o nazismo - o que vale também para outros casos de autoritarismo e carnificina praticados pelo Estado, e que encontramos à farta nas páginas da história -, quedamos sob a constante ameaça de que um evento parecido torne a romper, derramando sangue, com técnica e frieza, em nome de propósitos perversos e irracionais, pois, constatado que um expediente tão inimaginável e inconcebível quanto este foi possível num século a que se atribuía um generoso grau de esclarecimento, a verdade é que nunca estaremos inteiramente a salvo deste perigo. À conta desta incessante ameaça é que se coloca a necessidade imperiosa de testemunhar (embora se compreenda e respeite a decisão daqueles que, sobreviventes, preferiram silenciar).

Com tantas dificuldades, a narração das vítimas não poderia realizar-se livre de inconvenientes, tendo em consideração o caráter inconcebível do acontecimento. As terríveis situações a que foram submetidos os judeus e outros grupos étnicos durante a vigência do Terceiro Reich revelam um grau inimaginável de monstruosidade, ocorrendo, assim, a impossibilidade - ou grande resistência - de dizer, descrever, representar. Devido ao impacto do sofrimento, as vítimas não puderam processar e assimilar inteiramente o que Ihes sucedia. Trocando em miúdos, não lhes era possível dar com o sentido de tais cenas. Sobre isso, no capítulo "Literatura de testemunho: os limites entre a construção e a ficção", em O local da diferença (2005), Márcio Seligmann-Silva aventa que é impraticável traduzir a cena traumática de forma plena; simbolizar tal coisa passa muito além de nossas possibilidades de representação. O que podemos fazer é "reorganizar", "reinscrever", reapresentar o real - tomado, na esteira de Freud, por uma "cena traumática" -, o que difere da pretensão de descrever o que positivamente aconteceu. Esta opção de Seligmann-Silva vai de encontro ao modelo positivista de representação, que subscreve a ideia de que a relação entre o sujeito e o objeto é transparente, ao que o autor refuta |56| Revista Eletrônica Literatura e Autoritarismo, № 27 - janeiro a junho de 2016 - ISSN 1679-849X http://cascavel.ufsm.br/revistas/ojs-2.2.2/index.php/LA/index 
dizendo nunca haver uma transparência absoluta entre ambos, pois o texto se desdobra justamente sobre a brecha que separa o "original" da "leitura". Tal brecha, pois, é preenchida por obra nossa, segundo as impressões de cada um.

Alinhavados alguns caminhos pelos quais a teoria testemunhal sobretudo em âmbito germânico - se tem desenvolvido, pensemos agora sobre abusos de poder que encontraram terreno no Brasil. Para tratar deste caso de violência constitucional, o livro Brasil: nunca mais se nos revela um excelente ponto de partida, pois é a prova rotunda de que a ditadura militar brasileira, instituída com o golpe em 1964 e findada em 1985 com a saída do último general na presidência, fez um número expressivo de vítimas que, por defenderem ideais contrários àqueles perfilhados pelo governo, foram enviadas à tortura e à morte. Este livro é a síntese de um projeto de mesmo nome a que se dedicaram algumas pessoas engajadas em causas sociais, e conta com documentos que partiram das próprias autoridades brasileiras: processos políticos que transitaram pela Justiça Militar brasileira e, notadamente, pelo Superior Tribunal Militar, de 1964 a 1979, atestando, assim, os relatos de vítimas a que não se costuma dar crédito a pretexto de que são elementos que obedecem a motivações políticas. Enfim, este projeto, em formato de livro, serve ao propósito de vacinar o Brasil, conforme conta Dom Paulo Evaristo Arns, Cardeal-Arcebispo de São Paulo, em seu prefácio, contra a possibilidade de que aquelas práticas ignominiosas tornem a ter lugar, pelo que o destino de cada cidadão ficaria, novamente, ao temerário alvedrio de indivíduos facínoras, supostamente a serviço de instituições autoritárias.

No livro de poemas Inventário de cicatrizes, publicado em 1978, Alex Polari de Alverga põe à baila os padecimentos que experimentara na condição de prisioneiro durante o período de vigência da ditadura militar, por ocasião de sua participação no sequestro do embaixador alemão Ehrenfried Anton Theodor Ludwig Von Holleben. Preso em 1971, suportou nove anos de encarceramento, no que esteve sujeito aos mais aviltantes tipos de tortura que, futuramente, serviriam de indigesto alimento, de dramático conteúdo à sua obra. Compelido por um cuidado realista, as aflições, as reflexões e, no geral, os relatos no documento constados são veiculados por uma poesia clara, direta, referencial e objetiva, com preocupações, segundo o próprio, superiores Revista Eletrônica Literatura e Autoritarismo: Narrativa Testemunhal e Relações Históricas - ISSN 1679-849X |57| http://cascavel.ufsm.br/revistas/ojs-2.2.2/index.php/LA/index 
à estética, uma vez que ficcionalizam memórias de "vivência real", empírica, que, se descritas de outra maneira, perigariam esvaziar-se de seu autêntico sentido. Uma das discussões que estão na base do testemunho diz respeito à tensão existente entre ficção e documento, já que a locução "literatura de testemunho" une - acionando um conflito conceitual - estes dois contrários: "Tudo, absolutamente tudo neles, é vivência real, daí serem diretos e descritivos. Servem também para reter uma memória essencial, de outra maneira fadada a se diluir", dirá o poeta, acerca de seus poemas, em Camarim de prisioneiro (1980, p. 47).

Este cuidado voltado à preservação da realidade nua e crua que se the abatera é orientado, máxime, pelo temor de que tais crueldades, levadas a termo pelos militares, sofressem retoques e manipulações de tal ordem que terminassem por comprometer o seu teor factual - mesma preocupação demonstrada por Alfred Hitchcock ao filmar o Campo de Concentração de Bergen Belsen sem operar cortes, a fim de que tais imagens não caíssem em qualquer tipo de descrédito -, sem falar numa consequente atenuação de seu caráter sórdido, torpe, secamente real (CYTRYNOWICZ, 2003). Embelezamentos e aprimoramentos estéticos, na visão do poeta, passariam uma impressão bastante equivocada daquilo em que realmente consistia 0 cotidiano no cárcere, faltando à obrigação imperiosa de comunicar/transmitir toda a imundície nauseabunda que se desprendia dos locais em que as torturas tinham lugar e a que as vítimas estavam constantemente sujeitas. A coloquialidade é uma constante em sua poesia, como estratégia de conferir realidade e materialidade aos fatos narrados via poesia.

O poema a seguir, alocado no livro Inventário de cicatrizes, não foge a tais características, demonstrando comportar, como de praxe, o realismo subscrito por Polari:

\subsection{7}

Desembarcamos

os ferros foram lançados

no porto e nos pulsos

enquanto fomos expulsos

da vida e do continente

estando sujeitos ao pulsar

de incríveis sentimentos 
e ao sabor

das ondas e das contingências

rondamos em redor

das continências dos guardas.

Depois da viagem

da travessia e do enjoo

nos colocaram em uma sala

tiraram nossa roupa

nos revistaram, nos vestiram

nos revestiram de oco

e fizeram a chamada.

Ganhei um número de registro

e por um instante

perdi as esperanças.

(Polari, 1979, p. 23)

Realizada a leitura, a impressão que nos fica tem que ver com a condição animal a que Polari fora reduzido à medida que sua incursão naquele ambiente tétrico ia-se fazendo, qual sucedera a outros militantes feitos prisioneiros. O próprio título do poema, que veicula tão-somente o número de registro pelo qual ele seria designado doravante, corrobora tal leitura a ponto de não deixar dúvidas a respeito, considerando que esta substituição concorre como um dentre os fatores decisivos no processo de extravio da identidade, de coisificação. Para que tal impressão fosse insuflada a contento, ter-se-ia antes que proceder a um despojamento completo de tudo quanto o ligava à dignidade humana, à sua vida particular, processo levado a termo pelo isolamento imposto, por pressões psicológicas, pela aplicação de insuportáveis penas corporais e pela sujeição a situações vexatórias e degradantes. O referido desligamento tem seu exemplo máximo demonstrado, simbólica e positivamente, na substituição do prenome (elemento de individualização) por um número (elemento de generalização). Este número de que se fala, de uma forma ou de outra, afina com a linguagem administrativa, matemática, racional, pois opera como expediente de contagem e controle dos indivíduos - havidos aí como coisas - que foram concentrados nas prisões de todo o país. Esta ideia de "acúmulo" endereça-nos também à problemática das estatísticas, que estimulam um afastamento, mesmo uma indiferença, em relação à astronômica quantidade de pessoas a quem sucedem desgraças de toda a sorte, e com as 
quais não nos importamos precisamente por terem sido transformadas em números dos quais perdemos a conta. Enquanto o prenome, portanto, promove uma aproximação empática, o número promove, diametralmente, um afastamento frio. Com efeito, os algozes dispensavam um tratamento altamente animalizante aos prisioneiros, por quem não nutriam o menor sentimento de compaixão, por quem não demonstravam o mais remoto sinal de empatia.

Passemos, desta feita, ao destrinche de seus componentes internos, os quais sustentam e confirmam, gradativamente, a leitura proposta. O processo de coisificação desdobrado acima é habilmente marcado e desenvolvido por Polari à força do próprio ritmo empregado para a construção do poema, recurso estilístico que responde pela impressão criada de se estar à deriva no mar, "e ao sabor / das ondas e das contingências", o que induz à perda de si mesmo. Polari, ora cativo, é destituído de seu poder de decisão, pois já não responde pelos próprios passos nem pelo próprio destino, do que resulta esta impressão de estar à deriva, ao sabor das vagas, não mais senhor de si etc. (Registre-se, a propósito, que o poema rememora a entrada do poeta-guerrilheiro no Presídio de Ilha Grande.)

No primeiro verso, o ato de desembarcar aparece isolado e como que dando continuidade a uma situação que já estava em pleno curso: a de pessoas sendo encaminhadas (provadamente a contragosto) a um destino qualquer via embarcação. Este "desembarcamos" tem a eficiência de funcionar como um "desembarcamos, enfim", fazendo supor que tal início se dá apenas no âmbito do poema, e inaugurando, ainda, a chegada do sujeito (lírico?) a algum lugar que em tese ignoramos, o que, intuitivamente, levanta expectativas quanto ao que vem a seguir. No segundo verso, o ato realizado também é colocado em suspensão ("os ferros foram lançados"), para, no movimento subsequente, a palavra "ferro" ser investida de dupla significação ("no porto e nos pulsos"), pois faz referência tanto ao ato de aportar, de descer as âncoras, como ao ato de aferrolhar, de prender com grilhões, de aprisionar.

Já sabemos, portanto, que o destino que aguarda os elementos antes embarcados vai dar na privação de sua liberdade. Nos versos posteriores temos nossas suspeitas confirmadas: "enquanto fomos expulsos / da vida e do continente". Em paralelo à rima "pulsos e expulsos", sobrevém ainda a certeza |60| Revista Eletrônica Literatura e Autoritarismo, № 27 - janeiro a junho de 2016 - ISSN 1679-849X http://cascavel.ufsm.br/revistas/ojs-2.2.2/index.php/LA/index 
de que assistimos a uma rotina de encarceramento, que implica um rompimento da rotina daquele sujeito cuja liberdade é confiscada com a vida e com o continente, com tudo, enfim, que o fazia humano, coisa que Ihe causa sensação de isolamento, corroborada pela imensidão do mar simbólico que o separa das coisas sociais, e inclusive humanas. Esta viagem descendente (de que se falará adiante) a que os prisioneiros são encaminhados é, ela própria, o processo de coisificação pelo qual passa a vítima ao cuidado de algozes. A "travessia" da segunda estrofe corresponde, bem entendido, a esta passagem da condição humana à condição animal, que evolui para a perda do nome e culmina, inevitavelmente, no abandono das forças e da esperança.

Há que se observar, também, o efeito resultante da repetição sonora da consoante /p/, bilabial e explosiva: porto, pulsos, expulsos, pulsar, que se reitera no derradeiro verso: "perdi as esperanças". A impressão levada a efeito por esta aliteração é a de que os haveres dos cativos foram tomados pelo uso da força, da violência, e não de maneira branda ou coisa que o valha. Os prisioneiros veem-se vítimas de um autêntico arrebatamento, de um confisco impetuoso, veemente e impiedoso. Ainda na primeira estância, em matéria de sonoridade, há um jogo com as palavras continente, contingência e continência, formalmente similares. A palavra continente, aqui, provavelmente refere-se a uma extensão contínua de terra em que as nações se situam, dando a ver a exclusão da vida social que sucede aos prisioneiros. A palavra contingência, por seu turno, alude à incerteza quanto ao fado que os aguarda, já que seu futuro deriva de forças externas e independentes de sua vontade e escolha. Já o termo continência nos envia à questão da ditadura brasileira, por tratar-se de uma saudação militar. Somos advertidos, assim, de que os responsáveis pelo seu infortúnio são os militares.

Falemos, agora, do lugar que a referida descendência ocupa no poema com amparo em seus elementos estruturais, pois eles, neste caso, podem ser tão comunicativos quanto os significantes utilizados. Para começar, o poema é seccionado em três estrofes: a primeira contém onze versos, a segunda contém sete e a terceira, três, ou seja, as estrofes sofrem um déficit regular no número de versos. Note-se que a segunda estrofe ostenta, exatamente, quatro versos a menos em relação à primeira, e que a mesmíssima conta se verifica na terceira estrofe quando cotejada com a sua antecedente. Este gesto Revista Eletrônica Literatura e Autoritarismo: Narrativa Testemunhal e Relações Históricas - ISSN 1679-849X |61| http://cascavel.ufsm.br/revistas/ojs-2.2.2/index.php/LA/index 
descendente a que o poema alude se nos comunica não só pelo que expressam os termos empregados, mas igualmente pelo que expressa a sua estruturação mesma, em que se nota, de modo gradativo, uma subtração de seus elementos constitutivos. Pode-se dizer que os prisioneiros, na esteira das estrofes, também experimentam subtrações: "tiraram nossa roupa / nos revistaram, nos vestiram / nos revestiram de oco". Este despimento, que põe em evidência o estado aviltante a que os prisioneiros são reduzidos, tem lugar justamente na segunda estrofe, de cujos primeiros sinais de diminuição estrófica nos damos conta, ou seja, é um momento de ratificação das pretensões poéticas de Polari. A travessia pela qual erram os prisioneiros constitui um mecanismo de supressão de dupla envergadura, encarregada de sua morte moral e física, simultaneamente. De mais a mais, os versos de "12.207" denunciam a depravação dos verdugos, responsáveis diretos pela mácula que recai sobre a dignidade das vítimas, cujos corpos são amiúde tocados, devassados, violados, contra o que eles nada podem fazer (SALGUEIRO, 2011).

Na última estrofe, em que a subtração dos quatro versos é sentida, há o confronto entre o ganho de um número de controle e a perda das esperanças: "Ganhei um número de registro / e por um instante / perdi as esperanças". Note-se que, até então, o poeta referia simultaneamente os infortúnios em que ele e seus companheiros incorriam, de modo que era sempre utilizada a primeira pessoa do plural para tanto. No início da terceira e última estrofe, contudo, o poeta volta-se exclusivamente para si mesmo, cessando subitamente de referir os outros prisioneiros, para o que é usada a primeira pessoa do singular. Aqui, a impressão produzida é a de que seu isolamento fora levado às últimas consequências, mesmo porque é onde termina o poema. A esta altura, damos com um visível afrouxamento da palavra, do verbo, cuja perda de vigor provém da constatação de que inexistem razões para alimentar esperanças, pelo que sua conduta passa de algo esperançosa para lacônica, taciturna, desenganada etc.

Ao cabo da leitura, a que conclusão chegamos senão a de que o sujeito lírico se tenha calado - privado, enfim, do direito à palavra e à esperança após a conhecida e fatal subtração dos versos? A ausência de continuação, o término mesmo do poema, sugere, à luz de tais observações, a perda de quase |62| Revista Eletrônica Literatura e Autoritarismo, № 27 - janeiro a junho de 2016 - ISSN 1679-849X http://cascavel.ufsm.br/revistas/ojs-2.2.2/index.php/LA/index 
todos os pertences do sujeito lírico: da liberdade, da vida, da dignidade, do próprio corpo, da identidade, da esperança e, finalmente, da palavra, último recurso de que o privaram. A vida corpórea, no entanto, esta não lograram roubar, pois, do contrário, ser-lhe-ia impossível fazer-nos conhecedores de seus sofrimentos.

Ao fim, fica demonstrado que a dimensão estrutural e a dimensão diegética do poema estão correlacionadas, pois ambas se prestam ao serviço de comunicar as muitas subtrações de que o poema e o poeta foram vítimas. Noutras palavras, enquanto as estrofes vão sofrendo regulares supressões em seus versos, as vítimas vão perdendo, em dramática cadência, tudo aquilo que Ihes assegurava a dignidade e a identidade. Em "12.207", damos, portanto, com um engenhoso caso de isomorfia, visto que há correspondência entre a estrutura armada e os significados agenciados; dir-se-ia que a forma poética imita a coisa de que fala. A sucessão de perdas ficcionalizada tem seu limite no cessar do poema, instante máximo e derradeiro que simboliza a morte da palavra que se seguiu à morte da identidade e da dignidade. A escolha do número de registro para assentar no título é, por isso, sintomática: acusa a razão por que o prisioneiro se deixa vergar, uma vez privado do último recurso que lhe poderia restituir a dignidade, e acusa, também, o peso exercido pelo componente numérico em sua derrocada. Eis a redução do ser humano ao estado de coisa.

Em outro tempo e contexto, um conhecido poeta disse: "Perdi o bonde e a esperança. / Volto pálido para casa." (ANDRADE, 2006). O ano era 1934 e o livro, Brejo das almas. Mesmo desolado com o infortúnio, ao poeta de então restava ainda a opção de retorno ao lar. Décadas depois, vivendo em um regime político escancaradamente autoritário e repressor, que causou censura, exílio, prisão e centenas de mortes, a esperança parece, de fato, perdida. A locução "por um instante", verso que antecede o fecho do poema, funciona como que um suspiro, um alento, um momento de alerta ao poeta (ao cidadão, ao prisioneiro), dizendo que, sim, haverá cicatrizes, mas seu inventário mesmo em forma de livro de poemas - servirá de testemunho para futuras gerações. 


\section{Referências}

ADORNO, Theodor. O que significa elaborar o passado [1959]. Educação e emancipação. Trad. Wolfgang Leo Maar. Rio de Janeiro: Paz e Terra, 1995, p. 29-49.

AGAMBEN, Giorgio. A vergonha, ou do sujeito. O que resta de Auschwitz: o arquivo e a testemunha (Homo Sacer III). Trad. Selvino J. Assmann. São Paulo: Boitempo, 2008, p. 93-137

ANDRADE, Carlos Drummond de. $2^{2}$ reimpr. da $1^{\underline{a}}$ edição. Brejo das almas [1934]. Poesia completa e prosa. Rio de Janeiro: Nova Aguilar, 2006, p. 45.

ARNS, Dom Paulo Evaristo (org.). Brasil: nunca mais. 17. ed. Rio de Janeiro: Vozes Ltda, 1985.

CYTRYNOWICZ, Roney. O silêncio do sobrevivente: diálogo e rupturas entre memória e história do Holocausto. SELIGMANN-SILVA, Márcio (org.). História, memória, literatura: o testemunho na era das catástrofes. Campinas, SP: Editora da Unicamp, 2003, p. 125-140.

GAGNEBIN, Jeanne Marie. O rastro e a cicatriz: metáforas da memória. Lembrar escrever esquecer. São Paulo: Editora 34, 2006, p. 107-118.

GAGNEBIN, Jeanne Marie. Memória, história, testemunho. Lembrar escrever esquecer. São Paulo: Ed. 34, 2006, p. 49-57.

LEVI, Primo. É isto um homem?. Rio de Janeiro: Rocco: 1988.

LEVI, Primo. Os afogados e os sobreviventes. Rio de Janeiro: Paz e Terra, 1990.

POLARI, Alex. Inventário de cicatrizes [1978]. 4. ed. Rio de Janeiro: Global, 1979. [Publicado pela Global para Comitê Brasileiro pela Anistia / RJ e Teatro Ruth Escobar.]

POLARI, Alex. Camarim de prisioneiro. São Paulo: Global Editora, 1980.

SALGUEIRO, Wilberth. Da testemunha ao testemunho: três casos de cárcere no Brasil (Graciliano Ramos, Alex Polari, André du Rap). Prosa sobre prosa: Machado de Assis, Guimarães Rosa, Reinaldo Santos Neves e outras ficções. Vitória: Edufes, 2013, p. 299-319.

SALGUEIRO, Wilberth. Tortura sob deboche: uma questão de riso ou morte (análise de "Trilogia macabra", de Alex Polari). Anais do XII Congresso Internacional da Abralic. Curitiba: Abralic, 2011. v. 1. p. 1-10.

SELIGMANN-SILVA, Márcio. Reflexões sobre a memória, a história e o esquecimento. História, memória, literatura: o testemunho na era das catástrofes. Campinas, SP: Editora da Unicamp, 2003, p. 59-89. 
SELIGMANN-SILVA, Márcio. Literatura e trauma: um novo paradigma. O local da diferença: ensaios sobre memória, arte, literatura e tradução. São Paulo: Ed. 34, 2005, p. 63-80.

SELIGMANN-SILVA, Márcio. Literatura de testemunho: os limites entre a construção e a ficção. O local da diferença: ensaios sobre memória, arte, literatura e tradução. São Paulo: Ed. 34, 2005, p. 105-118. 